\title{
Job Negotiations in Academic Medicine: Building a Competency-Based Roadmap for Residents and Fellows
}

\author{
Rebecca A. Berman, MD, FACP' and Amy S. Gottlieb, MD, FACP \\ 'University of California, San Francisco, San Francisco, CA, USA; 2University of Massachusetts Medical School - Baystate, Springfield, MA, USA.
}

Negotiation skills are critical to career success, yet many physicians feel ill-equipped to negotiate for professional opportunities. Enhancing competencies in this arena may be especially critical for women and underrepresented minorities to reduce disparities in compensation and resources that begin upon entry into the workforce as junior faculty. This perspective offers a comprehensive overview of negotiation strategies and the job search process for individuals finishing medical training and seeking first-time employment. First, we extrapolate lessons from clinical medicine to provide a negotiation roadmap for residents and fellows. We use both a clinical and an employment scenario to illustrate the concept of principled negotiation in which negotiating partners elicit each other's values and interests and identify options for mutual gain. We then describe approaches to seeking and negotiating job opportunities and discuss typical timelines for these activities. We supply a list of professional needs to consider before a negotiation begins and introduce the concept of a best alternative to negotiated agreement to help ensure essential requirements are met in a final employment offer. Finally, we explore the utility of third-party assistance and published benchmarks and offer best practices for negotiating.

KEY WORDS: negotiation; women in medicine; pay disparity; career advice; career development.

J Gen Intern Med 34(1):146-9

DOI: $10.1007 / \mathrm{s} 11606-018-4632-2$

(c) Society of General Internal Medicine 2018

$\mathrm{N}$ egotiation skills are critical to career success. ${ }^{1}$ Research, as well as our own observations leading negotiation workshops, reveals that many physicians feel uncomfortable or are ill-equipped to negotiate for jobs or professional opportunities. $^{2-5}$ It is time to move the cultural needle, at the very least to help trainees launch themselves into fulfilling, productive careers. Enhancing negotiation competencies may be especially critical for women and underrepresented

Received February 20, 2018

Revised June 1, 2018

Accepted August 3, 2018

Published online October 1, 2018 minorities. ${ }^{6-8}$ Evidence suggests that these individuals experience disparities in compensation and access to resources important for professional success and that inequities begin upon entry into the academic medical workforce as junior faculty. ${ }^{9-15}$

We in the medical profession model and practice negotiation strategies routinely while providing care for our patients. ${ }^{16}$ Thus, we must recognize our collective experience and begin talking about negotiation with our trainees in the context of job seeking. Acknowledging that senior physicianfaculty may not feel confident initiating these types of discussions or have an arsenal of job-seeking experience to draw upon, we offer below a competency-based negotiation roadmap as well as some nuanced guidance. We anchor our approach within the context of a clinical scenario (see Text Box 1) to illustrate aspects of successful negotiation that exist within a typical professional endeavor.

Text Box 1: A clinical scenario illustrating key negotiation principles

A primary care physician suggests to her 50-year-old patient that he undergo a screening colonoscopy. The patient refuses.

- Appreciative inquiry to understand rationale, challenges, and interests

- Ask open-ended questions to understand why the patient does not want a colonoscopy. Perhaps he does not have easy access to

transportation, is afraid of complications, or worries about the bowel prep?

- Reflective listening

- Restating what the patient has said in his own words acknowledge the motivation behind his refusal and makes him feel heard.

- Identify options for mutual agreement

- By understanding the patient's concerns, the physician is better equipped to consider alternative options, like fecal immunochemical testing (FIT), which could provide comparable outcomes but may be more acceptable to the patient.

- Reference available evidence

- The physician uses data, like the patient's personal family history

of colon cancer, to underscore the importance this decision.

- Obtain agreement to continue to discuss

- If the patient is not yet ready to consent to FIT testing, the physiciar suggests that they should continue to discuss colon cancer screening at the next follow-up visit.

The clinical scenario provides an excellent example of what Fischer and Ury termed principled negotiation in their classic negotiation text, Getting to Yes, and is distinct from positional negotiation. ${ }^{17}$ Positional negotiation focuses on a specific viewpoint rather than on the ideas that engender a particular stance. Relying on positional negotiation, the physician in the case would insist that her patient needs a colonoscopy without initiating a dialogue with him about the recommendation. 
Conversely, principled negotiation rests on give and take as well as on appreciative inquiry, reflective listening, and identification and discussion of mutual goals.

Similar to thoughtful clinical care, successful negotiation often takes time and may require multiple conversations that build upon one another. The goal of a first negotiation encounter is to understand the other person's rationale, challenges, and interests and to gain agreement to discuss again. The doctor's understanding of the benefits of colon cancer screening and her successful efforts to elicit information from the patient about his perceived obstacles allow her to identify solutions that reflect evidence-based practice and address the patient's concerns. Text Box 2 illustrates how these same clinical skills could be applied to a job negotiation.

Text Box 2: Applying clinical skills to a job negotiation

A graduating resident seeking clinician-educator jobs would like to

work 4 days a week. Target clinic is looking for full-time physicians.

Approach could be:

- Appreciative inquiry to understand rationale, challenges, and

interests of medical director

- Applicant: "Tell me about the challenges faced by this clinic."

- Reflective listening

- Applicant: "It sounds like patient access is a concern and the

hospital is putting pressure on the clinic to expand hours."

- Identify options for mutual agreement

- After understanding the medical director's challenges, the applicant begins to suggest alternative options for the position like taking on

an evening clinic during four working days.

- Reference available evidence

- The applicant uses data on the number of clinical hours required

for a full-time position to support her suggestion for adding an

evening clinic to four working days.

- Obtain agreement to discuss again

- If the medical director is not ready to commit to a reconfigured position, the applicant states: "I'd like to think creatively about how

I can be part of a solution to improve patient access at this clinic.

Would you have time to talk in a few weeks?"

In addition to applying familiar clinical strategies to career negotiation, trainees (and those mentoring trainees) may benefit from the competency-based roadmap below. This roadmap provides a guide to seeking and negotiating a first position after residency or fellowship.

\section{COMPETENCY \# 1: NETWORKING}

It is critical to start the job search early. In academic medicine, new hires usually begin in July. Although networking in general is part of one's ongoing professional development, it should accelerate a year before graduation. This is an opportune time to introduce oneself, gain general job advice, and get on the radar of individuals who may ultimately be helpful in a job search.

Residents and fellows often find themselves seeking positions for which there are no formal job-postings, application processes, or deadlines. In order to identify potential opportunities, trainees should meet with program directors, mentors, senior colleagues, and peers the summer before graduation in order to share big-picture career interests (for example, research or medical education). Most people love to give advice, and in the process, individuals develop an understanding of a trainee's professional intentions, often become personally invested in his or her job search, and are able to provide introductions or recommendations. Additionally, if relocating to another city, reaching out to training program alumni in that geographic area to get an overview of the local marketplace is useful.

Professional societies are fertile ground to initiate jobrelated conversations and cultivate connections. Many have formal mentorship programs that allow access to senior faculty nationally. Attending regional and national conferences of these organizations should be a priority, if finances allow, in the year prior to a concerted job search. Going to sessions given by individuals at target institutions provides an opportunity to learn more about work being done at those organizations and creates a forum for personal introductions afterward.

At most academic medical institutions, the fiscal year begins October 1. Prior to that, few organizations can identify with certainty their capacity for new hires. For graduating trainees, job interviews will typically extend from the fall into the winter, and contracts may not be signed until early spring.

\section{COMPETENCY \#2: IDENTIFYING THE "ASK”}

Job negotiations are not just about salary. They should reflect all facets of one's professional life that impact career success. ${ }^{18}$ Everything is up for negotiation at the point of entry into an organization. Once a position has begun, it may be harder to request and obtain resources. Taking a flexible approach, rather than focusing on salary alone, offers more options to achieve a satisfactory negotiation outcome while allowing the future employer to safeguard equity with existing employees. In preparing for negotiation conversations, candidates should make an exhaustive list of professional needs (see Text Box 3) and rank order them.

Text Box 3: Alphabetical list of professional needs to consider in job negotiation

- Academic appointment and rank

- Benefits: Employer retirement matching (and when it vests), health insurance, dental insurance, life insurance, long-term care insurance, malpractice insurance, flexible spending accounts for healthcare and dependent care

- Call: Phone and in-house

- Continuing medical education allowance: Time and money

- Mentorship opportunities

- Professional expenses: Licensure/specialty certification and recertification cost coverage

- Protected and/or administrative time

- Relocation expenses/signing bonus

- Reporting structure: Organizational roles and structures can be

critical to one's career trajectory.

- Salary: Base and incentive and how that incentive is derived

- Space: Office, lab, clinical

- Staff support: Administrative, research, clinical

- Title

- Vacation time: Number of days and accrual method 


\section{COMPETENCY \#3: IDENTIFYING A BATNA AND PRIORITIZING PREFERENCES}

A Best Alternative to a Negotiated Agreement, i.e., a BATNA, is a term from the business literature to describe an identified backup plan for a failing negotiation. ${ }^{17}$ Each side has a BATNA. The more BATNA(s), the stronger one's negotiating leverage. In the context of job negotiations, BATNAs often refer to a candidate's other employment prospects that set the minimum standard for a position being negotiated. An alternative offer can be an effective BATNA only if it is a viable option that one is willing to pursue.

Additionally, within a particular job, there may be opportunities to leverage one's professional and personal priorities to gain a stronger negotiating position. Is salary more important than title? Is having no in-house call more important than the amount of telephone call? Is having a part-time research assistant more important than having an administrative assistant? Before any job negotiation takes place, candidates should identify and rank order these important preferences. Recognizing what is and is not a deal-breaker will make compromising on lesser-valued aspects of the negotiation easier. For example, if having guaranteed protected time is one's top priority, then compromising on other elements (e.g., base salary) will come more easily.

To establish BATNAs as well as a list of personal and professional priorities, one must first understand the marketplace. Obtaining objective data, similar to the clinical case above, soliciting input from experienced colleagues, and developing impressions from interviews for similar positions inform this process. Identifying concrete negotiating options based on self-reflection, evidence, third-party guidance, and, if possible, alternative job opportunities is critical. Having options engenders leverage at the negotiating table.

\section{COMPETENCY \#4: OBTAINING THIRD-PARTY ASSISTANCE}

Job negotiations can feel like an onslaught of details, rules, and regulations that often vary by state. It is useful to engage third-party assistance for support in the process.

Mentors can be helpful both to prepare for negotiations and, potentially, to advocate on one's behalf if things go awry. Although relying on a trusted mentor to read through job offers may be an option, we believe it is prudent to hire an attorney to do this work. A good attorney will help identify and keep track of critical details. For example, if negotiating for a part-time position, is call pro-rated in the contract? Although a lawyer will not typically negotiate the contract directly, she can offer useful advice and serve as a confidential resource. For example, one of our trainees hired an attorney who identified that a "noncompete" clause in her contract was standard in the trainee's target city. This knowledge allowed the trainee to redeploy her energies toward other aspects of the contract that were negotiable and thereby saved some of her negotiating leverage. The small monetary investment, approximately $\$ 500$, is worthwhile to ensure that terms of the employment agreement are clear and fair. There is no need to advertise the fact that an attorney has been consulted. Additionally, both mentors and attorneys can serve as reality checks as one revisits priorities and BATNAs that arise during the negotiation process.

\section{COMPETENCY \#5: NEGOTIATING}

Giving oneself permission and encouragement to negotiate is essential. Clinical training has provided the skills necessary for success. Similar to a challenging patient encounter, during a negotiation one must understand the negotiating partner's rationale, challenges, and interests. It is important not to get entrenched in a particular position. By getting a sense of each other's values and principles, parties can consider and identify areas of mutual benefit.

Separating the person from the problem is also critical. Again, as physicians, we are skilled at this approach. In a job negotiation, the personality of one's negotiating partner is not the problem that needs to be solved.

We recommend relying on market and institutional data to the greatest extent possible to support the negotiation. Additionally, asking alumni connections in a given city for local salary conventions may be useful. For those who feel uncomfortable asking about salaries, a mentor can help investigate local market practices as well. We strongly encourage obtaining salary information from national benchmarking sources. The Association of American Medical Colleges (AAMC) publishes a list of faculty salaries at US medical schools by geographic region and private versus public status. ${ }^{19}$ It is readily available for purchase but expensive. Medical Group Management Association (MGMA) is another salary resource but may be more difficult to obtain as an individual. ${ }^{20}$ Institutions often use a combination of these two benchmarks (AAMC and MGMA) to devise salary scales. Trainees should ask their program directors to borrow institutional copies of these resources, if they exist.

Most negotiations involve challenging moments. We recommend negotiating in person or, second best, by phone. Email and text tone can be misinterpreted and it is best to limit electronic communication during a negotiation when possible. If at a loss for words, using open-ended questions and reflecting back what was said can provide both parties time to gather thoughts and gain insights. If a negotiation comes to a standstill, asking for a break to think things over and then return to the discussion later is prudent. Negotiations take place over time. It is better to arrive at a positive outcome than to rush to an undesirable end.

\section{FINAL THOUGHTS}

Negotiating a job is a process with multiple points of contact. The first meetings should be introductory with the goal of 
presenting oneself, discussing career goals, and identifying how one might fit into an institution's broader vision. The main purpose of the first interview is to articulate one's career interests and skillset, to be enthusiastic about the job opportunity, and to learn more about the position and the needs of the institution. At this point, negotiations should be broad and focused on general desires. For example, 'I'm hoping to have a largely clinical job with some precepting and ideally some protected time for a medical education role." This is not the time to be negotiating salary or benefits. Once a position has been offered, then it is time to prioritize one's list of needs to determine the ask and begin discussing aspects of the position that are most personally important (e.g., more protected time). Negotiations often involve many meetings over several months, and some of the nitty-gritty details (like time allotted for continuing medical education) may be negotiated in the final stages once the contract has been drafted. Additionally, licensing, DEA application, and credentialing with insurance companies can take 4 to 6 months to finalize after committing to a job, and it is important to be aware that patient care cannot occur until these processes have been completed.

By harnessing negotiating skills honed in clinical training and using this competency-based roadmap, residents and fellows can begin their first position with the best chances for professional success. Faculty should encourage trainees to be intentional in their job negotiations and reinforce the message that what they want is out there. They only need to ask.

Corresponding Author: Rebecca A. Berman, MD, FACP; University of California, San Francisco, San Francisco, CA, USA (e-mail: Rebecca.Berman@ucsf.edu).

\section{Compliance with Ethical Standards:}

Conflict of Interest: The authors declare that they do not have a conflict of interest.

\section{REFERENCES}

1. Volkema RJ. Why Dick and Jane Don't Ask: Getting past initiation barriers in negotiations. Bus Horiz. 2009;52:595-604.

2. Sambuco D, Dabrowska A, Decastro R, Stewart A, Ubel P, Jagsi R. Negotiation in academic medicine: narratives of faculty researchers and their mentors. Acad Med. 2013;88:505-511.
3. Sarfaty S, Kolb D, Barnett $\mathbf{R}$ et al. Negotiation in academic medicine: a necessary career skill. J Womens Health. 2007;16:235-244.

4. Dawson R. Why do physicians have difficulty negotiating? The physician executive. 1999;25:43-44.

5. Malhotra D, Malhotra M. Negotiation strategies for doctors - and hospitals. Harv Bus Rev. 2013. Available at: https://hbr.org/2013/10/ negotiation-strategies-for-doctors-and-hospitals?autocomplete=true. Accessed July 18, 2018.

6. Holliday E, Griffith KA, De Castro R, Stewart A, Ubel P, Jagsi R. Gender differences in resources and negotiation among highly motivated physician-scientists. J Gen Intern Med 2015;30:401-7.

7. Stevens C, Bavetta A, Gist M. Gender differences in the acquisition of salary negotiation skills: The role of goals, self-efficacy, and perceived control. J Appl Psychol, 1993;78:723-735

8. Flores G, Mendoza F, Fuentes-Afflick E, Mendoza JA, Pachter L, Espinoza $\mathbf{J}$ et al. Hot topics, urgent priorities, and ensuring success for racial/ethnic minority young investigators in academic pediatrics. Int $\mathrm{J}$ Equity Health 2016:15:201.

9. Ly DP, Seabury SA, Jena AB. Differences in incomes of physicians in the United States by race and sex: observational study. BMJ 2016;353;i2923:1-8.

10. Blumenthal DM, Olenski AR, Jena AB. Sex differences in physician salary in US public medical schools. JAMA Intern Med 2016; 176:12941304.

11. Lautenberger D, Dandar V, Raezer C, Sloan R. The state of women in academic medicine: the pipeline and pathways to leadership, 2013-2014, Association of American Medical Colleges Washington, DC, December 15, 2014. Available at: https://members.aamc.org/eweb/upload/ The $\% 20$ State $\% 20$ of $\% 20$ Women $\% 20$ in $\% 20$ Academic $\% 20$ Medicine\%202013-2014\%20FINAL.pdf. Accessed July 18, 2018.

12. Freund KM, Raj A, Kaplan SE, Terrin N, Breeze JL, Urech TH, Carr PL. Inequities in academic compensation by gender: a follow-up to the national faculty survey cohort study. Acad Med 2016;91:1068-1073.

13. Weeks WB, Wallace TA, Wallace AE. How do race and sex affect the earnings of primary care physicians. Health Aff (Milwood) 2009;28:55766.

14. Jagsi R, Griffith KA, Stewart A, Sambuco D, DeCastro R, Ubel PA. Gender differences in salary in a recent cohort of early-career physicianresearchers. Acad Med 2013;88:1689-1699.

15. Sege R, Nykiel-Bub L, Selk S. Sex differences in institutional support for junior biomedical researchers. JAMA 2015; 314: 1175-1177.

16. Linson E. A systems approach to negotiation. SGIM Forum 2014;37(5):1.

17. Fisher R, Ury W, Patton B. Getting to yes. New York: Penguin Books; 2011.

18. Burton-Chase AM, Swartz MC, Silvera SA, Basen-Engquist K, Fletcher FE, Shields PG. Know your Value: Negotiation skill development for junior investigators in the academic environment - a report from the American Society of Preventive Oncology's junior members interest group. Cancer Epidemiol Biomark Prev 2015;24:1144-1148.

19. Association of American Medical Colleges. Faculty salary report. Available at: https://services.aamc.org/dsportal2/index.cfm?fuseaction=login. login\&thread=jump.FSSREPORTS \&appname=FSSREPORTS\&from permissionscheck=true. Accessed July 18, 2018.

20. Medical Group Management Association. Datadive provider compensation report. Available at: https://www.mgma.com/data/benchmarkingdata/provider-compensation-data. Accessed July 18, 2018 